\title{
RESEARCH OF THE EFFECT OF AGING PROCESS ON DISPERSION OF AIR PHASE AND ICE CRYSTALS IN MILK ICE CREAM
}

\author{
Antonina A. Tvorogova, Polina B. Sitnikova*, Tatyana V. Shobanova, Rumiya R. Zakirova \\ All-Russian Scientific Research Institute of Refrigeration Industry - \\ Branch of V. M. Gorbatov Federal Research Center for Food Systems of RAS, Moscow, Russia
}

\section{KEY WORDS:}

milk ice cream, aging, dispersion, air phase, ice crystals, overrun, dynamic viscosity

\begin{abstract}
In this research the results of analytical studies are presented, which prove the lack of data on influence of aging process on dispersion of structural elements in ice cream with fat mass fraction of $6 \%$ or less, and experimental studies on definition of dispersion of air phase and ice crystals in milk ice cream. It was found that the process of the mix aging doesn't significantly affect the dispersion of air phase and ice crystals in ice cream with fat mass fraction of $3 \%$. In ice cream with fat mass fraction of $6 \%$, made from a mix, the dispersion of the air phase increased along with the aging process, and the size of almost all air bubbles were less than 50 microns. At the same time the dispersion of ice crystals increased by no more than $10 \%$. The decrease in dispersion of the air phase during the storage period was observed, mostly in ice cream with a fat mass fraction of $6 \%$ produced of the cured mix. The research results have the practical importance as they justify the need for the aging process in the production of ice cream with a low mass fraction of fat and determine the necessity of further research in this area.
\end{abstract}

\section{Introduction}

The technology of dairy products provides that aging is the process of aging under certain conditions in order to achieve the intended physical, chemical or biochemical changes. Aging as an obligatory stage of the technological process of ice cream production was introduced along with the beginning of period of using the systems of stabilization with emulsifiers [1].

The main goal of this process is to achieve physical changes in the fat phase in order to obtain partially demulsified and agglomerated fat in the subsequent freezer process, which helps to stabilize the air phase. In addition, the presence of agglomerated fat and a stable air phase positively affects the dispersion of ice crystals.

The fat globules shells physically change due to the solidification of a major part of triglycerides at a aging temperature $(4 \pm 2){ }^{\circ} \mathrm{C}$, subsequent weakening of the bond between the fat globules and the shell protein, thus leading to desorption of the protein from the surface of the fat particles into the plasma. While that process the protein is replaced with emulsifiers intendedly introduced into the product as part of stabilization systems. As a result, the shells become less durable and during the freezing process, that follows the aging process, the shells partially destruct. Meanwhile the fat, that hasn't hardened during aging process, promotes the aggregation of fat particles [2]. Partially agglomerated fat is able to adsorb on the surface of air bubbles created during freezing process and, as a result, has a positive effect on the air phase stability [3].

The researches of aging process of ice cream mixes are not widely represented in scientific publications. A series of studies has shown the necessity of aging for the ice cream with a high mass fraction of fat of $10 \%-15 \%$, if the emulsifier is included into the ingredients of the ice cream $[2,3,4,5,6]$, while the type and composition of the fat component (milk fat, milk fat substitute or a combination thereof) provide no profound effect.

The paper [7] presents researches of ice cream with a mass fraction of fat of $8 \%$. The authors did not elicit the facts of agglomerates formation or any other change in the dispersion of fat globules during the aging of the ice cream mix at a temperature of $4{ }^{\circ} \mathrm{C}$. However in [8] the differences were found in the parameters of ice cream with a mass fraction of fat of $8 \%$ with aging and without aging in the process of the production.

It is important to note that the changes that occur in ice cream during aging are mentioned only superficially and there are prac- tically no researches devoted entirely to changes in the quality parameters of the product which occur during aging process.

In Russia the process of aging with the help of emulsifiers, which are applied as part of the stabilization system, is used for production of milk ice cream, high-fat ice cream (creamsicle) and extra rich ice cream (plombir). Taking into account that the production technology of ice cream with complex stabilizers-emulsifiers was borrowed abroad where its varieties with a mass fraction of fat of at least $10 \%$ (in less cases at least $7 \%$ ) are attributed to ice cream category, there is a question about the effect of the aging process on the quality parameters of the ice cream with low mass fraction of fat (up to 6\%).

\section{Materials and methods}

The objects of the research were the following:

$\square$ the milk ice cream with a mass fraction of fat of $3 \%$, produced without the technological operation «aging» (Sample 1);

$\square$ the milk ice cream with a mass fraction of fat of $3 \%$, produced with the technological operation «aging» (Sample 2);

$\square$ the milk ice cream with a mass fraction of fat of $6 \%$, produced without the technological operation «aging» (Sample 3); the milk ice cream with a mass fraction of fat of $6 \%$, produced with the technological operation «aging» (Sample 4).

The experimental samples were produced according to the traditional (conventional) technology with pasteurization at a temperature of $85^{\circ} \mathrm{C}$ and its exposing to this temperature for 5 minutes, followed by its cooling down to $4{ }^{\circ} \mathrm{C}$ and subsequent aging at a temperature of no higher than $5{ }^{\circ} \mathrm{C}$ for at least 5 hours before freezing - the samples 2 and 4 underwent this aging. The samples 1 and 3 were conveyed to freezing immediately after their cooling.

The researches were conducted in the laboratories of the All-Russian Scientific Research Institute of Refrigeration Industry - Branch of V. M. Gorbatov Federal Research Center for Food Systems of RAS.

The state and dispersion of the air phase and ice crystals were analyzed by the microstructural method with a microscope $C X 41 R F$ (Japan) with program control. The sizes of air bubbles and ice crystals were determined with Imagescope M software and their average sizes were calculated. Up to 10 images were obtained and processed in order to increase the accuracy and reliability of measurements for each sample [6,9]. 
Overrun was determined according to the procedure described in Appendix G of GOST 31457-2012 [10]. The method is based on measuring the mass of a fixed volume of the mix put into the freezer and the same volume of the air-saturated mix (ice cream) leaving the freezer. The overrun is calculated by the following formula:

$$
B=\frac{M_{2}-M_{3}}{M_{3}-M_{1}} \cdot 100,
$$

where $\mathrm{M}_{1}$ - weight of the cone, $\mathrm{g} ; \mathrm{M}_{2}$ - weight of the cone, filled with the mix, $g ; M_{3}$ - weight of the cone, filled with the ice cream, g; $100-$ factor of conversion to percent.

Dynamic viscosity parameters are analyzed with a viscometer «Brookfield DV-II + Pro» with Rheocalc V3.1-1 software, using a spindle SC4-31 and a $10 \mathrm{~cm}^{3}$ cuvette at a constant temperature $(4 \pm 1)^{\circ} \mathrm{C}$, with a spindle rotation speed $0,83 \mathrm{~s}^{-1}$.

\section{Results and Discussion}

Considering the significant effect on the state of the structure and dispersion of the air phase and ice crystals in ice cream mass with the initial viscosity of the mix and its overrun, the values of these parameters were determined at the first stage of research as follows (Table 1).

In the samples of mixes (2 and 4) subjected to aging, an increase in the dynamic viscosity of the mix which indicates the depth of physical changes in the fat phase, can be described as insignificant, the value is only $10 \%-11 \%$. When using the same stabilization system in ice cream with a mass fraction of fat of $10 \%$, the increase in viscosity reaches $70 \%[11,12]$.

Physical properties of the mix and ice cream

Table 1

Name of the parameter

Overrun, \%

The dynamic viscosity of the mix

The dynamic viscosity of the mix after aging, $\mathrm{MPa} \cdot \mathrm{s}$ before aging, $\mathrm{MPa} \cdot \mathrm{s}$

Values of the parameters

Sample 1 Sample 2 Sample 3 Sample 4

$\begin{array}{cccc}76 & 90 & 50 & 69 \\ 202 & 202 & 218 & 218 \\ - & 228 & - & 243\end{array}$

The aging process contributed to increase 1.18 times in product overrun in the sample with a mass fraction of fat of $3 \%$ and 1.38 times in the sample with a mass fraction of fat of $6 \%$. But it is necessary to note that all samples of the mix were characterized by good aerating capacity, achieved under freezing conditions without forced air supply at a threshold rate of at least $60 \%$.

When studying the dispersion of the air phase, it was found that the no aging of the milk ice cream mix with a mass fraction of fat of $3 \%$ has little effect on this parameter (Figure 1).

As it follows from the data shown in Figure 1, there are no differences in distribution of air bubbles size in ice cream with a mass fraction of fat of $3 \%$, made from a mix with aging and without aging. Differential curves of distribution of air bubbles size in ice cream after hardening and after 3 months of storage almost coincide.

The data in Figure 2 show that the greatest dispersion after hardening was achieved in milk ice cream with a fat mass fraction of $6 \%$ made from a cured mix, and the size of almost all air bubbles were less than 50 microns. After 3 months of storage the

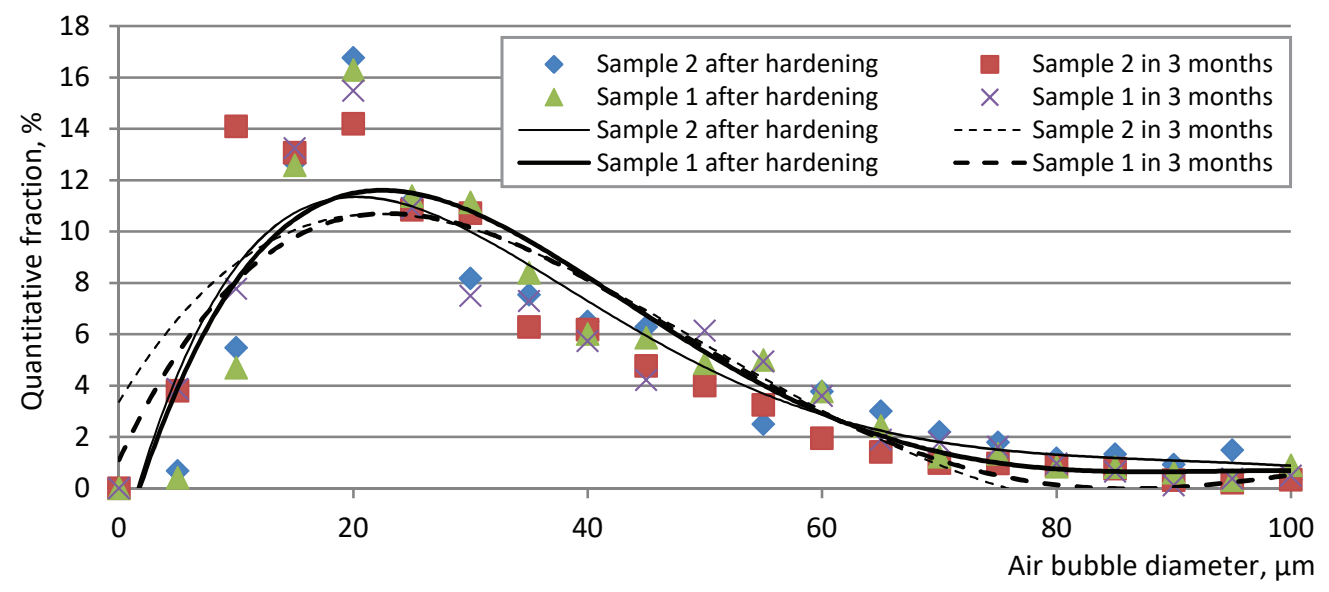

Figure 1. Distribution of air bubbles sizes in ice cream with a fat mass fraction of $3 \%$ is the following: after hardening and after 3 months of storage

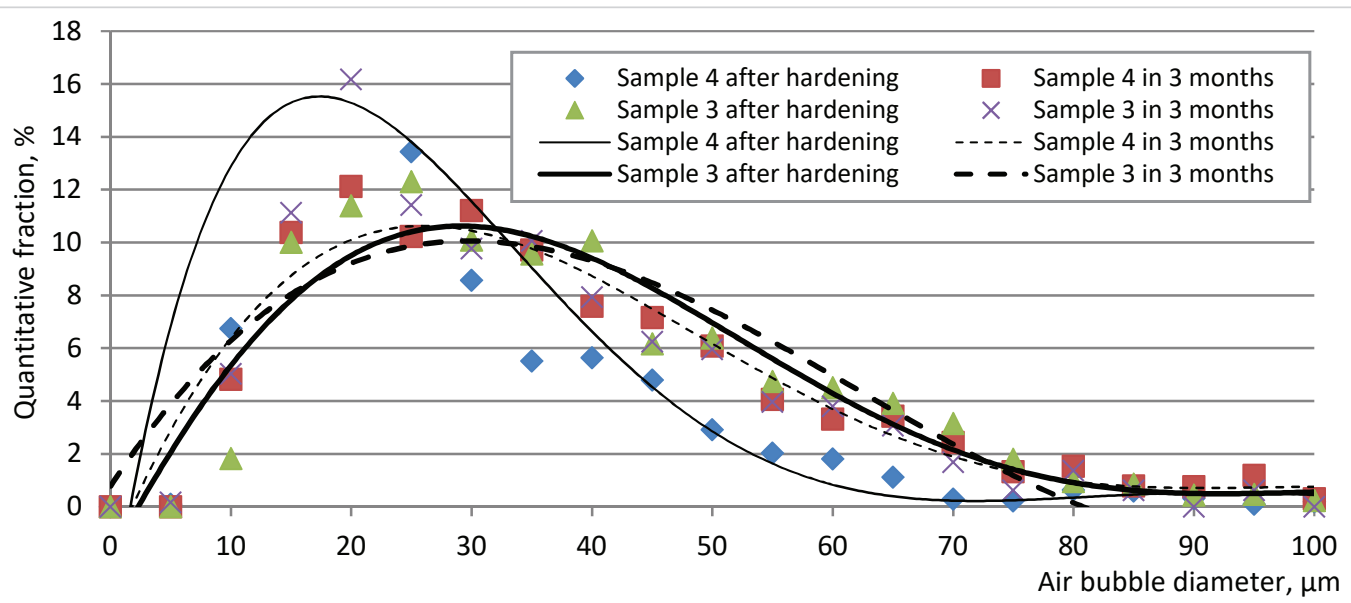

Figure 2. Distribution of air bubbles size in ice cream with a fat mass fraction of $6 \%$ after hardening and after 3 months of storage 
dispersion of the air phase in this variety of the ice cream significantly decreased, and was only slightly higher than in hardened ice cream made of uncured mix.

The effect of aging on dispersion of ice crystals is determined. The effect of aging on this parameter is expressed slightly, including the milk ice cream with a mass fraction of $6 \%$ (Figure 3 and Figure 4 ).

As follows from the data shown in Figure 4, the peak of the differential curve of the size distribution of ice crystals in the ice cream made from a cured mix and uncured mix, after hardening falls to $36 \mu \mathrm{m}$ and $32 \mu \mathrm{m}$; after 3 months of storage the peak is 37 microns and 33 microns respectively. Whereby the proportion of ice crystals of the above-indicated sizes is $13 \%$ and $15 \%$ in hardened ice cream, after 3 months of storage these values are $12 \%$ and $13 \%$.

\section{Conclusions}

As a result of studies it was determined that in the specialized literature there is no sufficient experimental data on the effect of the aging on dispersion of structural elements in ice cream with mass fraction of fat of $6.0 \%$ or less. The obtained experimental data prove the positive effect of aging on the dispersion of the air phase in ice cream with a mass fraction of fat of $6 \%$ after its hardening, and reduction of air phase dispersion during storage to almost the same level like the ice cream produced of uncured mix.

The process of aging of the ice cream mix with a mass fraction of fat of $6 \%$ leads to an increase in the dispersion of ice crystals by no more than $10 \%$.

The aging process provides positive effect on the aeration capacity of the mix. In samples with a mass fraction of fat of $3 \%$ and $6 \%$ the overrun of ice cream increases by 1.18 and 1.38 times respectively, compared with ice cream produced from an uncured mix.

The results of the research have the practical value for substantiation of aging process necessity in the production of ice cream with a low mass fraction of fat, and determine the need for further research in this area.

\section{Acknowledgment}

The article was published as part of the research topic No. 0585-2019-0043 of the state assignment of the V. M. Gorbatov Federal Research Center for Food Systems of RAS

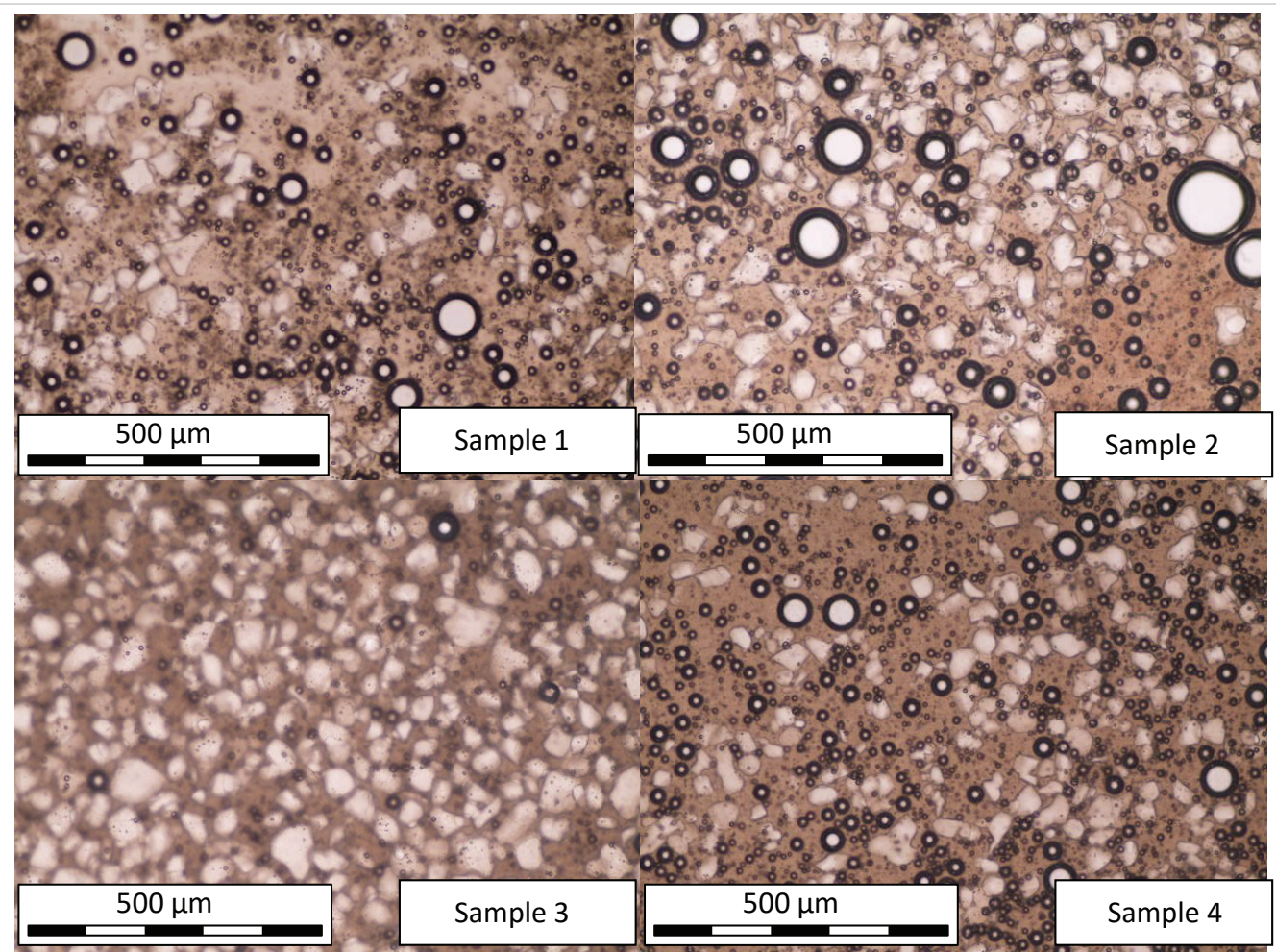

Figure 3. Microphotographs of ice crystals in experimental ice cream samples after their hardening

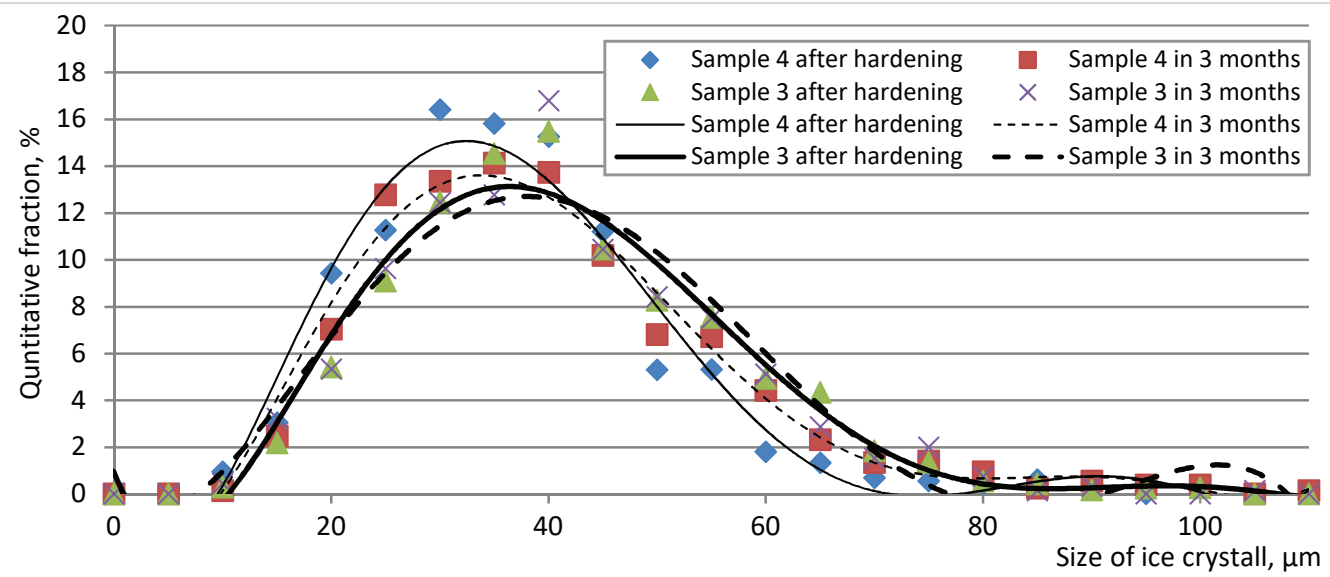

Figure 4. Size distribution of ice crystals in ice cream with a fat mass fraction of $6 \%$ : after hardening and after 3 months of storage 


\section{REFERENCES}

1. Stephanie Clark, S., Potter, D.E. (2007). Cottage Cheese. Chapter 26 in Handbook of Food Products Manufacturing. John Wiley \& Sons, Inc. 617633. https://doi.org/10.1002/0470113553, ISBN: 9780470049648

2. Tvorogova, A.A., Spiridonova, A.V., Rogozhkina, E.G. (2016).). Experimental substantiation of fats effect on the ice cream consistency. Kholodilnaya Tekhnika, 3, 49-53. (In Russian)

3. Tvorogova, A.A., Samoilov, A.V. (2011). Milk fat replacers for ice-cream. Dairy Industry, 5, 56-58. (In Russian)

4. Arsenieva, T.P., Brusentsev, A.A., Petrunina, Ye.B. (2008). Low-lactose creamy-and-vegetable ice-cream. Dairy Industry, 7, 57-59. (In Russian)

5. Bazmi, A., Launay, B., Cuvelier, G., Relkin, P. (2008). Impact of crystalline milk fat on rheological properties of ice cream mix emulsions during aging time at 4C. Journal of Texture Studies, 39(4), 309-325. https://doi. org/10.1111/j.1745-4603.2008.00145.x

6. Shobanova, T.V., Tvorogova, A.A. (2018). Influence of fat phase on technologically important indicators of ice cream plombir without emulsifier. Food systems, 1(2),4-11. https://doi.org/10.21323/2618-9771-2018-12-4-11 (In Russian)
7. Gelin, J. L., Poyen, L., Courthaudon, J.L., Le Meste, M., Lorient, D. (1994). Structural changes in oil-in-water emulsions during the manufacture of ice cream. Food Hydrocolloids, 8(3-4), 299-308. https://doi.org/10.1016/ s0268-005x(09)80342-1

8. Lucas, T., Wagener, M., Barey, P., Mariette, F. (2005). NMR assessment of mix and ice cream. Effect of formulation on liquid water and ice. International Dairy Journal, 15(10), 1064-1073. https://doi.org/10.1016/j. idairyj.2004.06.011

9. Sitnikova P. B., Tvorogova A. A. (2019). Physical changes in the structure of ice cream and frozen fruit desserts during storage. Food systems, 2(2), 31-35. https://doi.org/10.21323/2618-9771-2019-2-2-31-35

10. GOST 31457-2012 «Milk ice, ice-cream and plombir. Specifications». Moscow: Standartinform. -2012. - 24 p. (in Russian)

1. Goff, H. D., Hartel, R. W. (2013). Ice cream. New York: Springer, https://doi org/10.1007/978-1-4614-6096-1, ISBN: 978-1-4614-6096-1

12. Adleman, R., Hartel, R.W. (2001). Lipid crystallization and its effect on the physical structure of ice cream. Chapter 9 in the book: Crystallization processes in fats and lipid systems, 381-427. New York: Marcel Dekker. https://doi.org/10.1201/9781482270884, ISBN: 9780429175268

\section{AUTHOR INFORMATION}

Antonina A. Tvorogova - doctor of technical sciences, docent, Deputy Director, All-Russian Scientific Research Institute of Refrigeration Industry- Branch of V. M. Gorbatov Federal Research Center for Food Systems of RAS. 127422, Moscow, Kostyakova str., 12. Tel.: +7-499-976-09-63, E-mail: antvogova@yandex.ru ORCID: https://orcid.org/0000-0001-7293-9162

Polina B. Sitnikova- candidate of technical sciences, researcher, Laboratory of Ice Cream Technology, All-Russian Scientific Research Institute of Refrigeration Industry - Branch of V. M. Gorbatov Federal Research Center for Food Systems of RAS. 127422, Moscow, Kostyakova str., 12. Tel.: +7-495-610-83-85, E-mail: sitnikova.p.b@gmail.com

ORCID: https://orcid.org/0000-0002-4098-9146

*corresponding author

Tatyana V. Shobanova - junior researcher, Laboratory of Ice Cream Technology, All-Russian Scientific Research Institute of Refrigeration Industry- Branch of V. M. Gorbatov Federal Research Center for Food Systems of RAS.127422, Moscow, Kostyakova str., 12. Tel.: +7-495-610-83-85, E-mail: t.shobanova@yandex. ru

ORCID: https://orcid.org/0000-0001-6764-5020

Rumiya R. Zakirova - junior researcher, Laboratory of Ice Cream Technology, All-Russian Scientific Research Institute of Refrigeration Industry- Branch of V. M. Gorbatov Federal Research Center for Food Systems of RAS. 127422, Moscow, Kostyakova str., 12. Tel.: +7-495-610-83-85, E-mail: zrr-vnihi@yandex.ru ORCID: https://orcid.org/0000-0003-4455-7823

All authors bear responsibility for the work and presented data.

All authors made an equal contribution to the work.

The authors were equally involved in writing the manuscript and bear the equal responsibility for plagiarism.

The authors declare no conflict of interest

Received 21.04.2020 Accepted in revised 08.05.2020 Accepted for publication 14.05.2020 